\title{
NARRATIVE PLOT OF THE APOCALYPSE
}

\author{
Young Jang \\ Department of Old and New Testament \\ Stellenbosch University
}

\begin{abstract}
Since Aristotle, the plot of a narrative has been defined by two characteristics - causality and effects. The fivefold narrative-scheme (namely, constituents of a plot) proposed by Van Dijk, may be very well applicable to the Apocalypse, reflecting the two essential factors of its plot. The narrative plot consists of five phases - "introduction," "setting," "complication," "resolution" and "moral/coda."
\end{abstract}

\section{General}

Since Aristotle (Poetics 1450a 6) defined plot as "the arrangement of the incidents," two things have been considered as essential for the plot of a narrative, namely causality between events and their particular effects, which lead to the sequence and the rhetorical function of the narrative.

\section{Sequential perspective}

Forster ([1927] 1974:60) defines a story as "a narrative of events arranged in their timesequence," while a plot is "a narrative of events, the emphasis falling on causality" (cf. Scholes and Kellogg 1966:207, Barr 1995:23-33).

\section{Functional perspective}

Abrams (1999:224) states, "The plot in a dramatic or narrative work is constituted by its events and actions, as these are rendered and ordered toward achieving particular artistic and emotional effects (italics mine).",2

\section{Typical narrative categories of Van Dijk (1980)}

While various approaches to the plot of the Apocalypse exist, ${ }^{3}$ however, none seems to deal fully enough with the aspects of sequence and effect of the book. To this end, therefore,

1. He (1974:60) explains it through an example: “"The king died and then the queen died' is a story. 'The king died, and then the queen died of grief' is a plot." As far as plot is concerned, "time-sequence is preserved, but the sense of causality overshadows it."

2. Scholes and Kellogg (1966:212) formulate this as follows: "The reader of a narrative can expect to finish his reading having achieved a state of equilibrium - something approaching calm of mind, all passion spent. Insofar as the reader is left with this feeling by any narrative, that narrative can be said to have a plot."

3. (1) Linear plot: Many past interpreters tried to compose a linear structure of the book (cf. Lindsey (1970), Walvoord (1966)).

(2) Spiral movement: The narrative movement can be best illustrated as a spiral moving forward from the vision of the Lamb's enthronement to that of the Parousia (cf. Fiorenza (1985), Barr (1995)).

(3) Expanding scope: The narrative plot can be shown by the expanding scope of God's people, the kingdom of God, by degrees as the narrative goes (cf. Du Preez (1979)).

(4) U-Shape: The Apocalypse has a U-shaped plot that begins with a stable condition, moves downward into the unstable condition, and finally moves upward to a new stable condition (cf. Resseguie (1998)). (5) Christological Actions: Each movement in the Apocalypse turns on and reveals the saving and judging work of Jesus (cf. Du Rand 1991: 310-316, Barr 1984:39-50).

(6) Multi-Level Plot: Some scholars realized that there are different levels of narration in Revelation (cf. Boring (1992), Du Rand (1997)).

(7) Multilinear sequence: Stories range over a spectrum from simple, unilinear, tightly plotted sequences (e.g. a joke), to complex, multilinear, sequences (cf. Barr (1995)). 
another narratological approach will be proposed in this study.

According to Aristotle, a plot requires the basic elements of "a beginning, a middle and an end" (1450b 27). Since then, these three basic elements have been defined in more detail and variety. One of the most famous schemes would be that of the German critic, Freytag ([1863] 1887:374-394), who introduced an analysis of plot known as Freytag's Pyramid. The typical plot of a five-act play is described in terms of Introduction (with inciting moment), Rising Action, Climax, Falling action, and Catastrophe (Resolution). ${ }^{4}$ Although this pattern has been widely used in various ways, it can be applied only to a limited number of plays, as it lacks general appropriateness.

\section{The Plot of the Apocalypse}

Clearly, a more complex scheme is needed than the simple scheme of Freytag, one that reflects the relevant characteristics of the narrative plot of the Apocalypse. Van Dijk's fivefold scheme of a narrative seems preferable to any other scheme, as it consists of Setting, Complication, Resolution, Evaluation, and Coda/Moral.

\subsection{Setting (1:9-4:11) with preparation (1:1-8)}

The first typical category of narratives is the setting. Settings generally feature descriptions of the original situation, the time and place of the various episodes, a description of the main character(s) involved in these episodes, and possibly further background information about the social or historical context of the events ${ }^{5}$ (Van Dijk 1980:113-114, cf. Alter 1981:80).

While the narrative proper is always preceded by setting, stories also have all kinds of preparatory expressions, such as its title(s), and other attention markers. We do not include them in the proper narrative categories because they have a more general communicative function.

\subsubsection{The Preparatory Statement (1:1-8)}

According to Van Dijk's explanation of the plot of the Apocalypse, the first element is the beginning of the narrative (1:1-8). The preparatory part provides enough "general information" for the audience to follow the main narrative discourse. The notable constituents are (1) the title, (2) the attention markers, (3) the principle characters, (4) their (meaningful) relationship with the audience, and (5) the geographical location (Alter 1981:80; Van Dijk 1980:114):

(1) The title of the narrative discourse is "The Revelation of Jesus Christ"(1:1a).

(2) The beatitude in 1:3 " Blessed is he who reads aloud the words of the prophecy, and blessed are those who hear, and who keep what is written therein; for the time is near" would be enough of an attention marker to draw the attention of the audience in a situation of worship.

(3) The principal characters of the narrative are introduced as God, Jesus Christ, his angel, and John, who also play the roles of the principal enunciators in each narrative segment (1:1).

(4) Mentioning their particular relationship with the audience makes the hearers listen to this discourse more carefully, and makes them align themselves with the actions and ideas of the main characters in the narrative (1:5-6).

4. Modern literary critics prefer the term "Resolution" to the term "Catastrophe" for the last phase of the plot.

5. However, such settings may be very brief or even deleted when they are supposed to be known to the hearer. 


\section{In Medias Res}

Firstly, and without a doubt, all the NT books were written to centre on the work of Jesus to "save his people from their sins" (Mt 1:21; Rev 1:6). It is therefore worth noting the link between this book and the other NT books. The Apocalypse, which follows the Acts of apostles is the continuation of the gospel story until Jesus' second coming and his final salvation and judgment. The introductory section, therefore, provides a link with the previous stories: "To him who loves us and has freed us from our sins by his blood..." (1:5).

Secondly, the opening section of the Apocalypse mentions a representative event (Jesus' salvific act on the earth (1:5)), related to and closely preceding the event that precipitates the central situation or conflict. In this way, the narrative plunges us "in(to) the middle of things," at a critical point in the action. ${ }^{6}$ On the other hand, if we have to apply the story of Jesus' work to a much greater extent, from the beginning to the last days of the world, then again the structural beginning (sometimes called the "initiating action," or "point of attack") can be said to start "in the middle of things" (Abrams 1999:226-7).

\subsubsection{The Setting (1:9-4:11)}

Epiphany (1:9-20): Shifting from general statements to the main narrative.

This event proceeds to the main narrative, after general statements. That is, the epiphany leads John into the revelatory vision (the contents he has to deliver), starting with earthly and heavenly settings. The prominent features of Jesus Christ as the main character in this entry into the vision appear as fragments in the letters to the seven churches. The description of Jesus Christ foreshadows how he, as the Lord of the judgment and salvation, acts in the rest of story.

\section{The Earthly Setting (2:1-3:22)}

This part consists of seven letters through which we are made aware of the situation of the churches and their members in Asia Minor. Their situation is unstable, because of threats from without and within. ${ }^{7}$ A clue to this is given through expressions such as false apostles $(2: 2)$, the Nicolaitans $(2: 6)$, your tribulation and poverty (2:9), the slander of the Jews (2:9), the death of Antipas (2:13), some who hold the teaching of Balaam (2:14) and of the Nicolaitans (2:15), the woman Jezebel (2:20), many people who have soiled their garments (3:4), Jews who lie (3:9), many Christians in Laodicea who are lukewarm (3:16), as well as the reference to the banishment of John himself (1:9). The prevailing situation seems to be altogether inalterable.

The earthly setting, Asia Minor, can be indicated by the location of the seven churches $(2: 1,8,12,18 ; 3: 1,7,14)$, including the place of John's banishment (1:9). When we consider the words representing time (past, present, future) in this narrative, they should be interpreted according to the time this book was written, probably at the end of the emperor Domitian's rule over the Roman Empire. We must, however, note the "sudden disordered time settings" away from the standard time, which happen primarily in the interrupted events, or the heavenly events, such as "prolepsis" (flash forward), "analepsis" (flashback) and "achrony" (where chronological location to other incidents is ambiguous and

6. Abrams gives an example of this: "Shakespeare's Romeo and Juliet opens with a street fight between the servants of two great houses; the exposition of essential prior matters - the feud between the Capulets and Montagues. Shakespeare weaves it rapidly and skilfully into the dialogue of the startling initial scene" (1999:226)

7. Cf. Collins (1984:84-99). 
impossible to specify).

This part introduces Jesus Christ as the main character in $2: 1,8,12,18 ; 3: 1,7,14$, his followers (as his helpers), like Antipas ("his witness, his faithful one") (2:13) and the faithful or the conquerors $(2: 7,11,17,26-28 ; 3: 5,12,21)$ in each letter. Other important characters also appear, such as Satan or the devil (as Jesus' opponent) in 2:10, 13, 24 and his followers, like Balak "who hold the teaching of Balaam" (2:14); false apostles (2:2); the Nicolaitans (2:6); Jews ("a synagogue of Satan") (2:9; 3:9); some who hold the teaching of Balaam (2:14) and of the Nicolaitans (2:15); the woman Jezebel (2:20); and many people who have soiled their garments (3:4).

Transported to the heavenly court "in the Spirit" (4:2)

The focus of events shifts to the heavenly (stable) setting that is contrasted with the earthly (unstable) situation. The removal of John through the rapture of the Spirit indicates the vast gap between the two worlds. However, as events unfold, the stable state in heaven is to be realized on the unstable earth.

\section{The Heavenly Setting (4:1-11)}

This part shows "how it is" and "what is happening" in the heavenly court. The heavenly world is the place where "one seated on the throne" rules - that is, the will of God is completely fulfilled there. Therefore, there is no tension and conflict between opposite forces as on the earth. Instead, the heavenly court is shown in a perfectly stable state $(4: 4,5$, 6). The heavenly beings are praising and worshiping God. Nothing disturbs this atmosphere. Therefore 4:1-11 probably presents the heavenly setting so as to provide the static information about the well-ordered situation or context preceding the events, with a description of the main character(s).

Here the most important character is "one who is seated on his throne" (4:2). He, by implication, is the initiator of all heavenly and earthly events. When one of his creatures is displaced from the established order, he (now as a restorer) willingly tries to heal and restore it to the original (stable) state according to God's will (4:11). John is enraptured and transported into the heavenly court to see "what must take place after this" (4:1), to witness God's story of restoration.

\section{Two levels of narrative plot and homologue}

Here we notice that two levels of narrative plot, one for earthly events and the other for heavenly events, fork into two story lines from the beginning of the narrative. However, as the narrative goes through complication to resolution, the earthly and heavenly events converge at the end of narrative by means of the "New Jerusalem, coming down out of heaven from God" (21:2). Before that time, the heavenly events and earthly events closely influence each other. ${ }^{8}$ Consequently, every event theologically moves toward the complete homologue, ${ }^{9}$ the "stable state."

\subsection{Complication (5:1-11:19)}

According to Van Dijk (1980:113-114), a story typically brings an account of a complication representing "something that breaks the established norms, routines, expectations, balanced situation, or normal plans or goals of participants." This is an event that is

8. For example, the prayer of the saints on earth (6:17) initiates the heavenly answer (7:1-17); the Lamb (a heavenly being) opening one of the seven seals $(6: 1)$ initiates the event on the earth $(6: 2)$; in three sets of seven plagues, the heavenly liturgy $(5: 1-14 ; 8: 2-6 ; 15: 1-16: 1)$ precedes each of the seven plagues, etc.

9. On the usage of this term, see Thompson (1990:78). 
“dangerous, funny, or simply unexpected" for the participants.

What is complicating in one period or culture may not be so in others, so that we often do not understand the "point" of stories from other cultures. What is seen as a deviation from "normal" conditions is also culturally dependent (Van Dijk 1980:114). In the case of the suffering Christians of the Asia Minor, the Roman Empire seemed to be strong, steady, unwavering, long lasting, and indestructible. In this section of the narrative a process of amelioration and opposition/degradation is initiated (Via 1980:204). This will build up until the resolution or goal is arrived at the final phase of the narrative. Nobody could have imagined that the strong Empire, Babylon, could be destroyed. The Apocalypse, however, indicates that Babylon began to lose its stability. This came about the moment when "the Lamb took the scroll from the right hand of him who was seated on the throne" (5:7). Then she was no longer stable.

The complication is introduced and continued; the kingdom of Satan begins its degradation; its destruction will be confirmed in the "Resolution" phase.

In fact, God's power to disrupt the seeming stability of Babylon is implicit in the song of praise and worship of the heavenly beings. In its turn, heaven seems to be in balance until the Lamb is hailed (5:9). At this point, the heavenly court begins to initiate and respond to earthly events. The result is that the heavenly as well as the earthly situation becomes unstable or unbalanced. The conflict on the earth grows: the extent of the plagues introduced by the blowing of a trumpet (8:2-9:21, 11:14-19) is more serious than that of the plagues that followed the opening of the seven seals $(5: 1-6: 17,8: 1)$. In the meanwhile, the passages that interrupt the narration (A) $7: 1-8$ and (B) 7:9-17 appear to present the heavenly response to the question "who can stand before (the wrath of the Lamb)?" ([B'] 6:9-11) and the instruction of when "the number of their fellow servants and their brethren should be complete" ([A'] 6:12-17) respectively. ${ }^{10}$ In the case of the interruption of 10:1-11:13, the active heavenly reaction to "(the) prophesy about many peoples and nations and tongues and kings" (10:11) takes place in order to allow a last opportunity to repent and be saved, as the rest of mankind do not repent even after the sixth trumpet plague (9:21). The effort results in some people returning to God (11:13).

In conclusion, it is necessary to say that two points below support the view that the section from 5:1 to 11:19 corresponds to the phase of complication of the narrative plot:

Firstly, in chapter 5, John at first is frustrated when nobody comes forward to open the seals of scroll $(5: 4)$. But the sudden appearance of the Lamb to take the scroll and open its seals surprises and delights John and the heavenly beings (5:8-14). This unexpected action by the Lamb disturbs the present situation in heaven and on earth.

Secondly, from chapter 6 to chapter 11 , the complication is increasingly serious until a final action by the Lamb (to re-establish the original (stable) situation), takes place from chapter 12 to chapter 16, in the "resolution phase." The final boundary of Setting (chapter 4) and the starting boundary of Resolution (chapter 12) help to demarcate the extent of the Complication (chapters 5-11).

\subsection{Resolution (12:1-16:21)}

According to Van Dijk (1980:114-5), a resolution typically features a person's reaction to a previous event or action. "If the complicating event was undesired or counter to the goals of

10. A great deal has been written about the identity of the 144,000 as well as the relationship between the two vision (7:1-8 and 7:9-17) (cf. Du Rand 1991:275-6, Fiorenza 1991:65-8, Johnson 1981:484-5, Mounce 1977:164,171, Charles 1920:201-2). 
the participant(s), we may expect that the resolution will mention those actions that attempt the reestablishment of the original situation or the creation of a new situation in which further normal functioning is possible."

At this point we are interested in the resolution of the problem, or the termination of the conflict going on in the complication phase of the narrative. While the complication category should contain narratable and unexpected events, the resolution category requires the participant's (re-)action to the preceding events. This idea can be applied to the section ranging from 12:1 to $16: 21$.

The appearance of the Lamb, as the initiator of the complication, to take the scroll and to open its seals (5:9) agitates the seemingly static or stable state of the heavenly court that reflected the result of the patient endurance of Jesus waiting for people to repent and turn to God until this moment, when he seeks to prevent the loss of anyone whose name is written in the Lamb's book of life (21:27; Jn 18:9). The same is true of the earth where the unreal static or stable state is the result of the false peace in the seemingly mighty Roman Empire. Both heavenly and earthly settings turn into the clamorous conditions of two opposing camps when warfare is at hand.

No further repentance and the radical action of Jesus against the power of the Satan. Jesus starts to harvest on the end day. In this phase that lasts until the trumpets have been blown, it seems that he no longer makes an effort to get people on the earth to repent. Only the harvest with the reaping of the earth, which seems to indicate "salvation" (14:14-15), and the gathering of the clusters of the vine of the earth that seems to mean "judgment" $(14: 17-20)$ remains. Jesus' efforts to save those who repent continue to the last, but only up to the trumpet plagues. He aims not to lose anyone who repents and turns to God (Jn 18:9, cf. 17:2). Consequently, some seem to repent after the prophecy of two witnesses $(11: 13)$. After this, no repentance takes place during the plagues of the bowls; instead "they cursed God" $(16: 9,11,21)$. On the part of Jesus, there is therefore no need to continue in conflict with evil powers, and there is no need to patiently await further repentance; instead all complication is to be settled or resolved without delay $(10: 6)$ by means of his response to the slain saints' call of judgment (6:10).

\section{Resolution as a complete large narrative unit}

In observing the following pattern, the parallel structure of the two parts as a pair is important insofar as it underscores the demarcation of this section as a complete narrative unit.

A (12:1-17) Heavenly flashback (the birth of Jesus; the dragon is thrown down to the earth at myth level)

B (13:1-18) Beasts killing the saint, as a parody of Jesus on the great day ${ }^{11}$

C (14:1-20) Harvesting on the end day (symbolic action of salvation and judgment)

A' (15:1-16:1) Heavenly liturgy for pouring out the seven bowls

B' (16:2-16) Plague falling on the beast's worshipper (16:2) and the throne of the beast $(16: 10-12)$, but no repentance among men $(16: 9,11)$ and three foul spirits assembling the kings of the world for battle on the great day (16:12-16)

C' (16:17-21) Destruction of the great Babylon

( $A$ and $A^{\prime}$ : Setting centred on Jesus; $B$ and B': Complication centred on Beast; $C$ and

$C$ ': Resolution centred on "the end day")

11. In this part, we find the dramatic parody of Satan and his servants. The parody of Satan parallels the judging action of the Lamb at the great day. The beast from the earth kills the faithful, as Jesus smites the nations with the sharp sword from his mouth (19:11-21). 
Climax is "the moment in a play or story at which a crisis reaches its highest intensity and is resolved. The major climax may be preceded by several climaxes of lesser intensity" (Beckson \& Ganz 1989:43). The same is true of the narrative of the Apocalypse. Several small waves with less powerful climaxes (such as opening seals and blowing trumpets, and symbolic action of harvesting at the great day) have occurred but their climaxes were just precursors for the final great moment. ${ }^{12}$

\subsection{Evaluation 17:1-22:5}

According to Van Dijk (1980:115), "We may expect that the central events and actions of a story be evaluated by the participant and/or narrator in the category of evaluation. Evaluations feature the global mental or emotional reaction of the narrator participant with respect to the narrated episode: whether it was nice, awful, funny, etc. (Italics mine). Here the specific expressive function of stories appears most clearly: they record not merely what happened to us but also what it did to us."

\section{The evaluation expressed by the mental or emotional reaction}

The complication $(5: 1-11: 19)$ is finally settled in the resolution phase of the narrative, peaking with the fall of Babylon (16:17-21). But John would probably feel the necessity to show the evaluation of the central events and actions of a story via the participant and/or narrator. For this purpose, John skilfully deals with these aspects in full in the "Evaluation" phase of the narrative.

In the meantime, the evaluation phase often carries an "emotional overtone" expressed by the participants or the narrator. This is especially true of the evaluation of this book (17:1-22:5), in that the whole of chapter 18 and almost half of chapter 19 (19:1-10) consist of global mental/emotional expressions of "the fall of Babylon" such as "mourning" or "exclamation" or "delighting" or "praising," expressed by the various participants of the narrative, while the whole of 21:1 to 22:5 also states John's radiant impressions of "the New Jerusalem." In this way, John skilfully presents the central events and actions of the narrative story to be evaluated.

\section{Thematic order rather than chronological order}

Just after the seventh bowl is poured out as the resolution of God, its final outcome is shown at length. Firstly, John is transported, in the Spirit, into the wilderness (17:30) to see the outcome of the judgment against the harlot, and then, similarly, unto a great high mountain $(21: 10)$ to see the outcome of the vindication of the bride. The sharp contrast between the visions of the harlot and the bride as many scholars have noted units. The contrast between them serves to frame the literary unit, which is structured in chiastic form. This means that the sequence is developed thematically in inverse order, rather than chronologically. ${ }^{13}$

12. In the case of the opening of the seal, the harbinger of the great day, its peak (6:12-17) is followed merely by silence $(8: 1)$ that, however, still anticipates a happening. In the case of the trumpet blowing, the peak (9:1321) leads only to the twenty-four elders' praise and announcement of "it is the time for the dead to be judged and for the servants to be rewarded" (11:16-18), in response to loud voices in heaven (11:15). In the case of the symbolic action of harvesting on the end day, the great day is still awaited as the climax. It is not until "the pouring of bowls" on the end day that all kinds of complications are resolved.

13. Chapters $17-22$ has been an exegetical Gordian knot, especially in a chronologically sequential framework (e.g. Charles 1920, 2:144-54). 


\section{The chiastic structure}

We have to note that this evaluation section $(17: 1-22: 5)$ seems to repeat the climax of the resolution phase which already occurred with the seventh bowl plague in detail. But this section is no longer part of the sequential framework, being thematic and logical. The thematic development of this final outcome can be displayed roughly in the chiastic frame. ${ }^{14}$

The song of the 24 elders in 11:18 proclaims that the time has arrived "for the dead to be judged, for rewarding thy servants, and for destroying the destroyers of the earth." As the climax of the heavenly response to that, the seventh of the bowl-pouring plagues results in two outcomes concerning the dwelling places of the Satan's followers and the Lamb's followers (A vs. A) accompanying two outcomes concerning the judgment of the dead according to their deserts (B vs. B'):
(A) 17:1-19:21 the fall of Babylon
(B) 20:1-6 "the first resurrection": the faithful came to life again, and reigned with Christ for a thousand years
(B') 20:7-15 "the second death": any one whose name was not found written in the book of life, was thrown into the lake of fire.
(A') 21:1-22:5 the establishment of the New Jerusalem

Additionally, to confirm that this section, as a complete unit, has a thematic chiastic arrangement, it would be helpful to consider other studies supporting this perspective in various ways. Snyder (1991:440-450) and Bauckham (1993:18-21), for example, would support it, because Snyder proves the chiastic framework within this section, while Bauckham deals with the chiastic relationship between the preceding part (chaps 5-16) and this section (chaps 17-22).

The chiastic frame supports the fact that the events in the complication or resolution phase often follows sequential order, while the evaluation phase often emphasizes thematic development through the mental/emotional expression of participants, or the narrator. This also helps to confirm that this section (17:1-22:5) belongs to the evaluation rather than the resolution category.

\subsection{Moral/Coda $(22: 6-21)^{15}$}

According to Van Dijk (1980:115), "The general pragmatic function of narratives, finally, appears in the well-known category of Coda or Moral. Such a moral draws a conclusion so to speak from the events for further actions, both of the hearer and of the speaker (italics mine)."16

What are the characteristics of the moral in 22:6-21?

This section definitely exhibits typical characteristics of the Moral phase of the narrative, because desirable actions are requested from the audience and serious warnings are pronounced against undesirable actions.

The desirable actions are as follows: "Blessed is who keeps the words of the prophecy

14. See Smith (1994:387,392), Bauckham (1993:18-21), Snyder (1991:446-449), Giblin (1974:487-504).

15. As a number of interpreters have shown, the verbal correspondence between the introductory part (1:1-20) and the concluding part (22:6-21) of the text is important insofar as it underscores the demarcation of this section as a complete narrative unit.

16. E.g. I'll never take him on a vacation again! 
of this book" (22:7); "Worship God" (22:9); "Do not seal up the words of the prophecy of this book, for the time is near" $(22: 10)$; “... the righteous still do right, and the holy still be holy" (22:11); "Blessed are those who wash their robes" (22:14); "The Spirit and the Bride say, 'Come.' And let him who hears say, 'come' "(22:17).

Meanwhile, the warnings are expressed as follows: "...if any one adds to them God will add to him the plagues described in this book" (22:18); "if any one takes away from the words of the book of this prophecy, God will take away this share in the tree of life..." (22:19). That which is seen as desirable and undesirable action for the audience, occurs in half (8) of the total verses (16) of this section (22:6-21). This means that the moral aspect occurs in as much as 50 percent of the verses. The fact that the call for action and the warning against vice (or immorality) is concentrated in this section, indicates that this section definitely corresponds to the "Coda/Moral" part, the last narrative category.

In connection with this "moral" section, it would be helpful to find out what "a code of conduct" for participants in the narrative would be, because desirable conduct in the narrative should continue to be required even after reading of the narrative. For example, God wants to restore his creation (21:5), Jesus executes judgment and salvation for the sake of God's will (12:18), the saints should witness to God's word and Jesus (1:9,10:11), the rest of people including some Christians who have fallen away should repent of their sin and turn to God (8:4).

We may well detect such codes of conduct for each main character in the moral section.

The code of conduct for God, "the water of life" in 22:17 and "the tree of life and in the holy city" in 22:19, etc. is implied in the completion of his aim - namely, the "restoration" of his creation into the original state. God wanted to restore the unstable world to a stable world $(21: 3,22: 2)$. Now, it has been done on earth as it is in heaven. Now it is done! $(17: 17 ; 21: 6)$. As for the code of conduct for Jesus Christ, "I am coming soon, bringing my recompense, to repay every one for what he has done" (22:12) implies his mission to complete God's will. In other words, Jesus is sent to the earth to fulfil God's intention of restoring all of creation to its original state. Therefore Jesus' actions on the earth and after his ascension into heaven are related to God's goal. His main mission in completing God's aim would be through the salvation of his followers and the judgment of Satan and his followers. The code of conduct for the saints, which is implied in 22:10, 16 and so on, suggests that his angel or the saints should witness (or show) the churches "what must soon take place" (22:6). In other words, the mission of the saints, like John's, is to live "their life of witness". Finally for the rest of people, expressions such as "those who wash their robes" $(22: 14)$ and "outside are the dogs ...." (22:15) urge them to repent and to turn to God. In other words, the wayward Christians or the people of the world should repent of their evildoing and worship only God, instead of worshipping their idols.

Thus, the code of (particular) conduct for each participant can be shown as follows:

God: $\quad$ Restoration

Jesus: $\quad$ Salvation and Judgment

The saints: Witness

The rest: Repentance.

Consequently, the narrative plot proposed by Van Dijk (viz., the narrative categories: setting, complication, resolution, evaluation, moral/coda) proves more detailed and more conclusive than other suggestions of plot, which shows movement forward from an unstable state to a stable condition, epitomized by the New Jerusalem, with an eschatological moral ending. 


\section{BIBLIOGRAPHY}

Abrams, MH 1999. A Glossary of Literary Terms. Orlando, FL: Harcourt Brace College Pub. Alter, R 1981. The Art of Biblical Narrative. New York: Basic Books.

Barr, DL 1984. The Apocalypse as a symbolic transformation of the world: A literary analysis. Interpretation 38, 39-50.

- 1995. Using Plot to Discern Structure in John's Apocalypse. Proceedings of the Eastern Great Lakes and Mid-West Biblical Societies 15, 23-33.

Bauckham, R 1993. The climax of prophecy. Studies on the Book of Revelation. Edinburgh: T\&T Clark.

Beckson, K \& Ganz, A 1989. Literary Terms A Dictionary. NY: The Noonday Press.

Boring, ME 1992. Narrative Christology in the Apocalypse. CBQ 54, 702-723.

Charles, RH 1920. A Critical Commentary on the Revelation of St. John. New York: Scribner's Sons.

Collins, AY 1984. Crisis and Catharsis: The power of the Apocalypse. Philadelphia: Westminster.

Du Preez, J 1979. Die Koms van die koninkryk volgens die boek Openbaring. Annale Universiteit van Stellenbosch, vol 2, serie B, No 1. Kaapstad: Nasionale.

Du Rand, JA 1991. Johannine perspectives: Introduction to the Johannine Writings. Midrand: Orion.

1997. ‘... Your kingdom come ... on earth as it is in heaven ...' The theological motif of the Apocalypse of John. Neotestamentica 31(1), 59-76.

Fiorenza, ES 1985. The Book of Revelation: Justice and Judgment. Philadelphia: Fortress. 1991. Revelation : Vision of a just world. Minneapolis: Fortress.

Forster, EM (1927) 1974. Aspects of the Novel. New York: Penguin Books.

Freytag, G 1887. Die verlorene Handschrift: Roman in fünf Büchern. Die Technik des Dramas (vol 2). Lepzig:Hirzel.

Giblin, CH 1974. Structural and Thematic Correlations in the Theology of Revelation 16-22. Bib 55, 487-504.

Jang, Y 2001. A Narratological Approach to the Structure of the Apocalypse of John. Unpublished DTh dissertation, University of Stellenbosch: Stellenbosch.

Johnson, AF 1981. Revelation, in Gaebelein, FE ( ed.), The Expositor's Bible Commentary. Grand Rapids: Zondervan.

Lindsey, H 1970. The Late Great Planet Earth. Grand Rapids: Eerdmans.

Mounce, RH 1977. The Book of Revelation. NICNT. Grand Rapids: Eerdmans.

Resseguie, JL 1998. Revelation Unsealed: A Narrative Critical Approach to John's Apocalypse. Leiden: Brill.

Scholes, R \& Kellogg, R 1966. The Nature of Narrative. New York: Oxford University Press.

Smith, CR 1994. The Structure of the Book of Revelation in the Light of Apocalypse Literary Conventions. NovT 36, 373-93.

Snyder, BW 1991. Triple-Form and Space/Time Transitions: Literary Structuring Devices in the Apocalypse. SBL Seminar Papers, 440-450.

Thompson, L 1990. The book of Revelation: Apocalypse and Empire. New York: Oxford.

Van Dijk, TA 1980. Macrostructures: An interdisciplinary Study of Global Structures in discourse, Interaction, and Cognition. Hillsdale: Lawrence Erlbaum Asssociates.

Via, DO 1980. Structure, Christology, and Ethic in Matthew, in Spencer, RA ( ed.), Orientation: Studies in Literary Criticism and Biblical Criticism. Pittsburgh:Pickwick.

Walvoord, JF 1966. The Revelation of Jesus Christ. Chicago: Moody. 